have been described in a recent issue of Rural Research (23, Sept. 1960). The technique used in the experiments consisted of heating scale-infested fruit in ovens at different temperatures and for different periods of time. The effect of heat on fruit was therefore examined but not the possible damage to trees. It was found that all the scales could be kjlled by a temperature of $70^{\circ} \mathrm{C}$. maintained for $1 \mathrm{hr}$. This treatment, however, resulted in severe damage to the fruit. Equally effective 'kills' were obtained at a temperature of $50^{\circ} \mathrm{C}$. kept up for $21 \mathrm{hr}$. During this treatment the fruit was not damaged. Increasing the humidity during the $50^{\circ} \mathrm{C}$. treatment did not alter the time necessary to kill the scale, and it is apparent that high temperature rather than dehydration was the direct cause of death. Further experiments have involved treating the trees themselves. The technique used was to enclose the trees in plastic sheets and utilize solar energy as the heat supply. Some difficulty has been experienced in maintaining temperatures at a safe level.

\section{Congelifraction of Clays}

THE clay fraction of soils is customarily regarded as a product chiefly of chemical rather than mechanical processes. While chemical alteration is undoubtedly necessary to produce clay minerals in the first place from the components of erystalline rocks, it now seems that at least one form of mechanical weathering, namely, congelifraction, can be effective in reducing particle size well down into the clay grade in unconsolidated sediments. I. C. MeDowall (N.Z.J. Geol. and Geophys., 3, 337 ; 1960) has investigated the effects of alternate freezing and thawing on water-saturated samples of kaolinite, vermiculite, halloysite, and weathered clays containing illite and halloysite. The particle size distributions were determined at intervals by the Andreason pipette method, and it was found that appreciable reduction of particle size occurred during 800 cycles. The process appears to operate on particles at least as small as $1 \mu$, and is most rapid in those minerals where the bonding between the basal planes of component sheets of the clay mineral is weakest. In cold climates the process might therefore be an important one in the formation of plastic clays, perhaps particularly of fireclays.

\section{Navigation down the Centuries}

A sHoRT review of navigational methods from the earliest times to the present, with special emphasis on the newest techniques with Earth satellites, is made in a 24-page publication of the Coast and Geodetic Survey of the United States Department of Commerce, entitled Use of Artificial Satellites for Navigation and Oceanographic Surveys, by Paul D. Thomas (Technical Bulletin No. 12. Pp. $i+24$. Washington, D.C.: Government Printing Office, 1960. 25 cents). The first half of the publication is a historical review, beginning with Hipporchus and Ptolemy, touching on Galileo, the French expeditions of the seventeenth and eighteenth centuries, and the development of the marine chronometer, before coming to radar systems, Loran and inertia navigation. The second half of the paper is devoted to Earth satellites. Here the main interest is in the transit system of satellites, already in action on an experimental basis, from which position can be obtained by interpretation of the Doppler shifts of the radio-waves received from the satellites.

\section{Use of Superconductors for producing Strong Magnetic Fields}

THE production of strong magnetic fields by the use of superconductivity phenomena would appear to be considerably advanced by the development of a new superconducting compound of niobium and tin, $\mathrm{Nb}_{3} \mathrm{Sn}$, by the Bell Telephone Laboratories. The distinctive property of this material is its ability to retain superconducting properties even when exposed to fields of about 90,000 oersteds, and possibly even higher, while carrying currents of approximately 100,000 amp. em.-2 (see Kunzler et al., Phys. Rev. Letters for February 1, 1961). The new material is very brittle, but by packing a narrow niobium tube with appropriate quantities of powdered niobium and tin, sealing the ends of the tube with niobium plugs, reducing the tube by swaging and drawing it, a wire of $0.015 \mathrm{in}$. diameter which can be wound into a solenoid coil is formed. On heating the wire to about $1,000^{\circ} \mathrm{C}$., the inner materials react to form $\mathrm{Nb}_{3} \mathrm{Sn}$, and the necessary superconducting properties are developed. Owing to mechanical difficulties associated with the substance at high fields, a large solenoid of the material has not yet been wound, but it is anticipated that these difficulties will be overcome within the next twelve months.

\section{The Iron and Steel Institute, the Institute of Metals and the Institution of Metallurgists}

The Councils of the Iron and Steel Institute, the Institute of Metals and the Institution of Metallurgists have recently examined the problems of closer co-operation between these three societies. After careful consideration they have concluded that amalgamation of the three societies would not be practicable within the foreseeable future. The three Councils, therefore, decided to set up a permanent Joint Consultative Committee of the three societies, which will meet regularly and advise their Councils on all activities and questions of common interest.

\section{Lederle Medical Student Research Fellowships}

The Lederle Laboratories Division of the American Cyanamid Co. announces that it is making available fellowships to medical schools throughout the United States and Canada for the year 1961. These fellowships, in amounts not exceeding 600 dollars a year for any one individual, are intended to relieve in part the financial burden of students who desire to devote their summer vacations to research in the preclinical departments. Students who apply for Lederle Medical Student Research Fellowships must have the consent of the faculty member under whose supervision their research is to be conducted. Further information can be obtained from the Lederle Laboratories, American Cyanamid Co., Pearl River, New York.

\section{Carlsberg-Wellcome Travelling Research Fellow- ships, 1961-62}

Applications are invited for the CarlsbergWellcome travelling research fellowships, 1961-62, the object of which is to encourage co-operation, on an exchange basis, between Danish and British research workers in any branch of the natural sciences which has a bearing on human and animal medicine. One fellowship annually is awarded to a candidate from the United Kingdom for a year's work in Denmark and one annually to a Danish 